\title{
Soldagem em Operação: Parte 1 - Efeito do Arrefecimento Causado pelo Fluido em Tubulação de Espessura 11 mm
}

\author{
(In-service Welding: Part 1: Effect of Freezing Caused by Fluid in 11 mm thick Pipe)
}

\author{
Paulo Faria ${ }^{1}$, Jefferson Pinto Soares ${ }^{2}$, Francisco Felipe da Silva Araujo ${ }^{1}$, Ronaldo Paranhos ${ }^{2}$ \\ ${ }^{1} U O / B C-P E T R O B R A S$, Macaé, RJ, Brasil,pfaria@petrobras.com.br \\ ${ }^{2}$ UENF-CCT-LAMAV, Campos dos Goytacazes, RJ, Brasil,paranhos@uenf.br
}

\begin{abstract}
Resumo
Este trabalho avalia, na soldagem em operação, a influência do arrefecimento causado por um líquido fluindo em contato com a parede interna de uma tubulação sendo soldada por TIG (GTAW) e eletrodo revestido (SMAW). A soldagem foi realizada na ligação de conexões de aço ASTM A105 a um tubo API 5L Gr X60 com espessura de $11 \mathrm{~mm}$ e de $6 \mathrm{~mm}$. A circulação do fluido foi feita com água potável em duas faixas de temperatura, de 6 a $10^{\circ} \mathrm{C}$ e 26 a $36^{\circ} \mathrm{C}$. Foram simuladas quatro juntas soldadas, avaliadas por meio de ensaios não destrutivos (inspeção visual, líquido penetrante, partículas magnéticas e ultrasom). Esta parte do trabalho apresenta os resultados dos ensaios destrutivos (tração, dobramento, impacto, fratura e dureza) e análise macrográfica e micrográfica para o tubo de $11 \mathrm{~mm}$ de espessura. As juntas soldadas não apresentaram os problemas típicos da soldagem em operação, como trincas a frio e risco de perfuração. Os procedimentos de soldagem puderam ser qualificados, atendendo os critérios de aceitação das normas pertinentes. Foi possível concluir que o resfriamento acelerado causado pelo fluido em circulação, elevou consideravelmente a taxa de resfriamento na superficie interna do tubo. O efeito do arrefecimento causado pelo fluido no interior do tubo foi mais significativo que a temperatura deste fluido, tendo provocado o aumento na dureza da zona fundida e zona termicamente afetada e reduzido o alongamento no ensaio de tração, porém ainda em valores adequados para o tubo de $11 \mathrm{~mm}$ de espessura.
\end{abstract}

Palavras-chave: Soldagem em Operação, Arrefecimento, TIG, Eletrodo Revestido.

\begin{abstract}
This work evaluates for in-service welding, the influence of cooling caused by a liquid flowing in contact with the inner wall of a pipe being welded by TIG (GTAW) and stick electrode (SMAW). The welding was done to join connections of an ASTM A105 to an $11 \mathrm{~mm}$ and $6 \mathrm{~mm}$ thick API $5 \mathrm{~L} \mathrm{Gr} \mathrm{X60} \mathrm{steel} \mathrm{pipe.} \mathrm{The} \mathrm{fluid} \mathrm{circulation} \mathrm{was} \mathrm{made} \mathrm{with} \mathrm{potable} \mathrm{water} \mathrm{within} \mathrm{two} \mathrm{temperature} \mathrm{ranges,}$ of 6 to $10^{\circ} \mathrm{C}$ and 26 to $36^{\circ} \mathrm{C}$. Four welded joints were simulated, evaluated by non destructive testing (visual, penetrant, magnetic and ultrasonic). This part of the work shows for $11 \mathrm{~mm}$ thick pipe the results for destructive testing (tensile, bending, impact Charpy V, fracture and hardness) and by macrographic and micrographic analysis. The welded joints did not presented typical problems of inservice welding, such as cold cracks and the risk of burn through. It was possible to conclude that freezing caused by the circulation fluid significantly increased the cooling rate in the inner wall of the pipe. The freezing effect of the fluid itself inside the pipe was more significative than the temperature of this fluid, having promoted increase in hardness of the fusion zone and heat affected zone and reduced elongation in the tensile testing, but still with adequate values for $11 \mathrm{~mm}$ thick pipe.
\end{abstract}

Key-words: In-service weldig, Cooling, GTAW, GMAW.

\section{Introdução}

A soldagem em operação é uma técnica onde se realiza a solda com o movimento ou fluxo contínuo de fluidos no interior da tubulação de processo ou duto, sem a necessidade de paradas operacionais. Pode ser realizada para reparos diretos na parede, reforços e instalação de conexões para posterior trepanação [1].

A soldagem em operação diferencia-se da soldagem convencional, pois utiliza processos de soldagem de baixa

(Recebido em 19/09/2011; Texto final em 28/06/2012). energia e está associada a um escoamento acelerado de fluidos no interior do tubo. Como conseqüência, o ciclo térmico de soldagem é alterado, a velocidade de resfriamento tende a ser significativamente maior, trazendo riscos inerentes à fragilização da microestrutura e aumento da dureza.

Há dois riscos potenciais a serem considerados na soldagem em operação: a formação de trincas a frio e o excesso de penetração do cordão de solda na parede do duto, podendo causar a perfuração do tubo.

As trincas a frio podem surgir devido à alta concentração de hidrogênio na solda (proveniente do revestimento dos eletrodos, caso não recebam tratamento adequado), a uma microestrutura susceptível (martensita ou bainita), à presença de tensões residuais elevadas e à baixa temperatura [2]. É característica de 
processos de soldagem de baixa energia, podendo ocorrer na zona termicamente afetada (ZTA) e na zona fundida (ZF) [3].

A perfuração da tubulação poderá ocorrer caso a área não fundida adjacente à poça de fusão não tenha resistência suficiente para suportar as tensões provenientes da pressão interna da tubulação [4]. O risco de perfuração é devido à sobrepenetração do arco, sendo função da espessura da parede, dos parâmetros de soldagem e das condições de operação do duto (vazão, pressão, temperatura e propriedades térmicas do fluido). A penetração aumenta com o aumento do aporte térmico. Este risco diminui à medida que se reduz a penetração da solda e se aumenta a espessura da parede da tubulação.

A perfuração da tubulação durante a soldagem normalmente não leva a rupturas catastróficas, porém, uma parada total do sistema de escoamento se torna necessária [4]. No entanto, resulta no vazamento do fluido e em problemas para a segurança do soldador e operadores do sistema. Além do perigo físico do vazamento em si, o produto pode ainda ser tóxico ou inflamável.

Processos de soldagem de baixo hidrogênio, tais como TIG e eletrodo revestido com revestimento tipo básico, associados a um aporte térmico baixo, resultam numa condição de menor penetração. Mas, na soldagem de tubos de espessura mais elevada, onde o risco de perfuração é menor, a adoção de aporte térmico mais elevado, para minimizar o risco do aparecimento de trincas a frio, é um procedimento freqüentemente utilizado.

Este trabalho foi realizado originalmente como uma
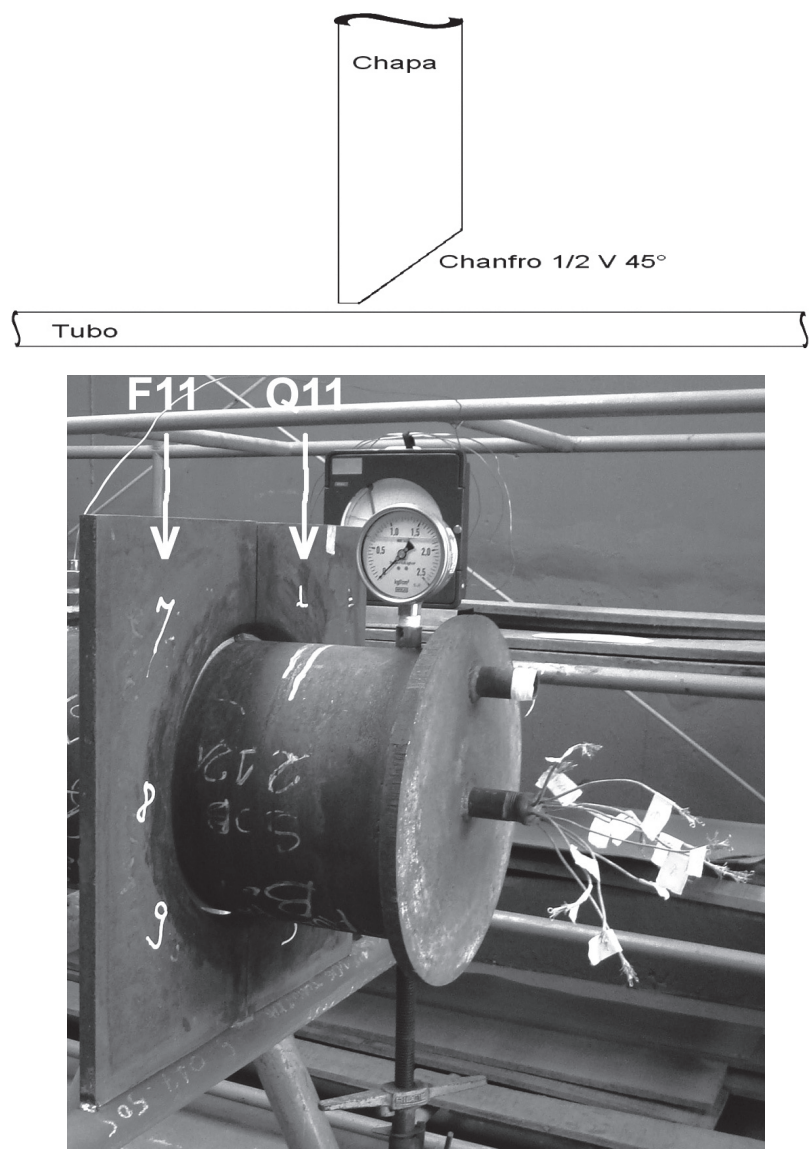

Figura 1. Detalhes do Aparato Experimental. (a) Detalhe Típico da Junta do Experimento; (b) Aparato Experimental e Posição das Soldas; (c) Detalhe da Solda e Fluxo do Experimento. dissertação de mestrado [5] junto ao programa de pós-graduação de engenharia e ciência dos materiais da UENF, no intuito de simular a soldagem em operação envolvendo a união de conexões a tubos de $11 \mathrm{~mm}$ e $6 \mathrm{~mm}$ de espessura, com fluxo continuo de água durante a soldagem. Foram testadas duas faixas de temperatura do fluido interno (temperatura ambiente e em torno de $10^{\circ} \mathrm{C}$ ). A seguir, foram avaliadas as taxas de resfriamento, as propriedades mecânicas e modificações microestruturais dos materiais provocadas pela soldagem em operação.

Esta parte do trabalho descreve o procedimento experimental usado para a simulação da soldagem e os controles realizados durante a soldagem de tubos de $11 \mathrm{~mm}$ e de $6 \mathrm{~mm}$ de espessura para avaliar o efeito da temperatura do arrefecimento na soldagem em operação. São avaliadas as propriedades da união de conexões a um tubo de $11 \mathrm{~mm}$ de espessura, com fluxo continuo de água durante a soldagem. Os resultados para os tubos de $6 \mathrm{~mm}$ de espessura serão comentados em uma segunda parte, a ser publicado posteriormente.

\section{Materiais e Métodos}

O tubo utilizado foi um API 5L X60 com diâmetro nominal $12^{\prime \prime}$ (323 mm) e espessura da parede de $11 \mathrm{~mm}$. Parte do tubo foi usinada radialmente para a espessura de $6 \mathrm{~mm}$. As conexões foram feitas com quatro chapas ASTM A572 Gr50 de espessura $22 \mathrm{~mm}$, cuja composição química e soldabilidade são similares

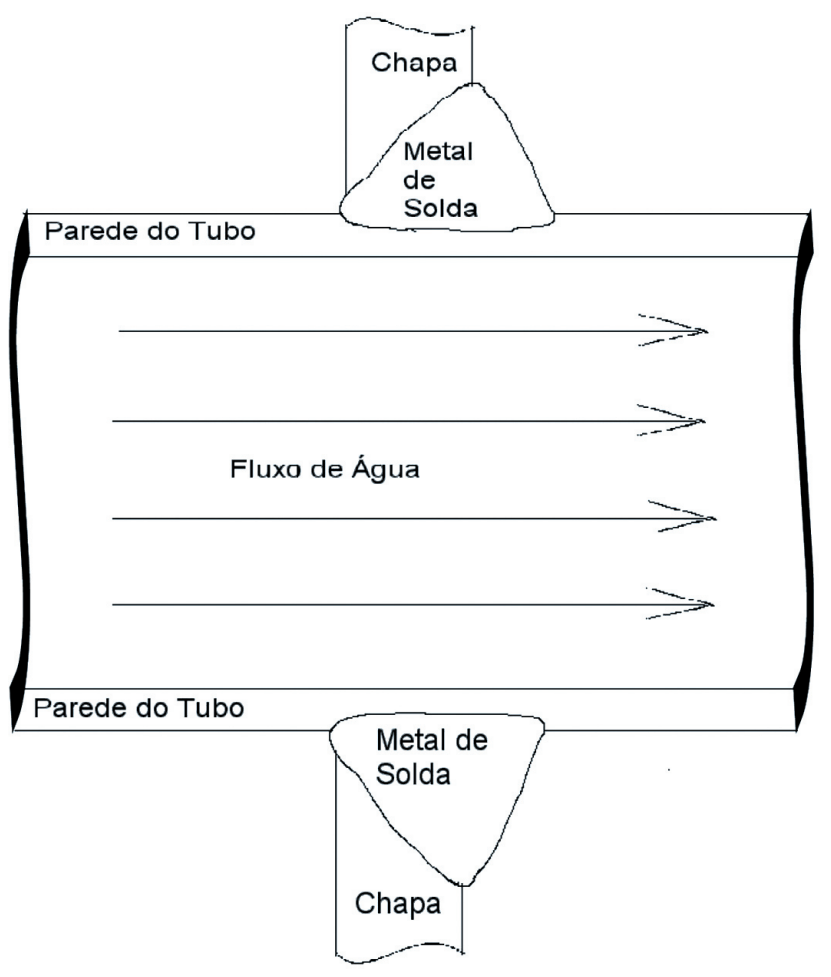


às conexões reais, fabricadas conforme a norma ASTM A105 [6]. A composição química destes materiais foi testada por análise com um espectrômetro de emissão óptica.

Soldagem: foram executadas quatro juntas de ângulo, com $500 \mathrm{~mm}$ de comprimento cada, soldadas com penetração total, cujo aparato experimental é mostrado na Figura 1. No intuito de avaliar os efeitos do resfriamento acelerado causado pelo fluido interno, foram testadas duas situações: uma com fluxo à temperatura ambiente e outra com o fluxo resfriado abaixo de $10^{\circ} \mathrm{C}$. As soldas foram identificadas como: Q11: solda ligando uma peça à parte do tubo com $11 \mathrm{~mm}$, com o fluxo à temperatura ambiente; F11: solda ligando uma peça à parte do tubo com 11 $\mathrm{mm}$, com o fluxo à temperatura abaixo dos $10^{\circ} \mathrm{C}$. Q6: solda ligando uma peça à parte do tubo com $6 \mathrm{~mm}$, com o fluxo à temperatura ambiente; F6: solda ligando uma peça à parte do tubo com $6 \mathrm{~mm}$, com o fluxo à temperatura abaixo dos $10^{\circ} \mathrm{C}$.

Os processos de soldagem utilizados foram TIG com corrente contínua polaridade direta (CCPD) no passe de raiz e reforço da raiz, utilizando varetas classe ER70S-3 [7] com gás de proteção Argônio 99,99\%. A seguir, foi utilizado eletrodo revestido classe E7018 [8], com corrente continua polaridade inversa (CCPI), para os passes de enchimento e acabamento. Os soldadores foram previamente qualificados, nos dois processos, em procedimento de soldagem convencional.

Controle Durante a Soldagem: A circulação do fluido no procedimento Q11 e Q6 foi realizada com água à temperatura ambiente. Nos procedimentos F11 e F6, a circulação foi realizada com água resfriada artificialmente, com a adição de gelo picado

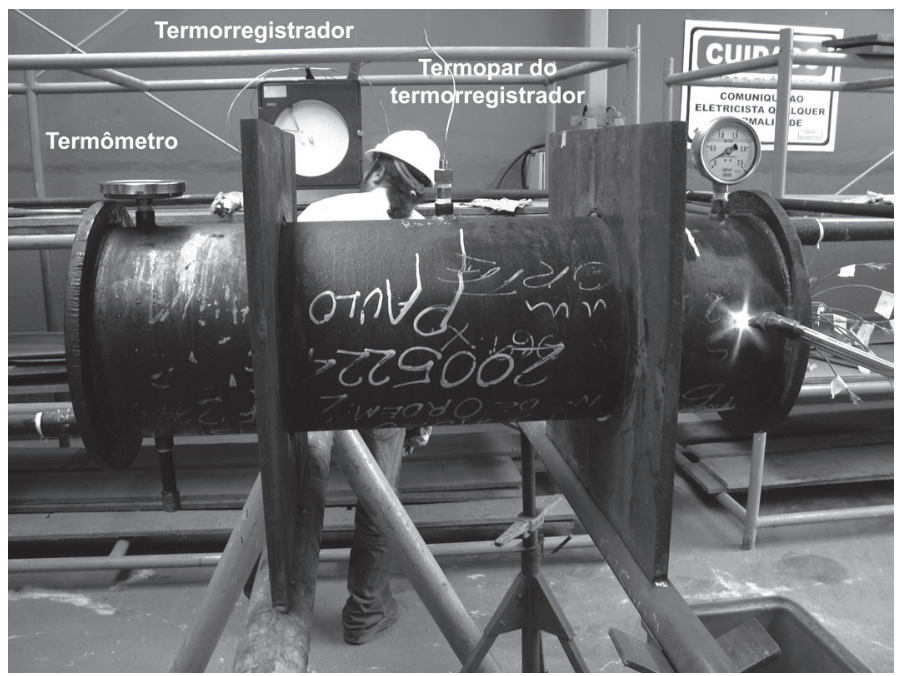

(a)

na caixa d'água, que possibilitou a obtenção de temperaturas de fluxo abaixo dos $10^{\circ} \mathrm{C}$, durante toda a soldagem. As variáveis do fluxo no interior do tubo, como pressão, vazão, velocidade de escoamento e regime de escoamento foram mantidas fixas (veja Tabela 1). Durante a soldagem, as variáveis do processo foram medidas: intensidade de corrente e tensão com um multímetro; a velocidade de soldagem foi calculada pela relação entre o comprimento da solda e o tempo gasto para sua realização. Também foi medida a largura do cordão depositado (oscilação).

O controle da temperatura do fluido foi realizado utilizando um termômetro analógico, instalado no tubo o próximo à entrada de água, como mostra a Figura 2. O registro destas temperaturas foi feito, de forma continua, através de termorregistrador ligado a um termopar, que foi instalado no meio do tubo, na parte superior (veja Figura 2). Serão apresentadas apenas as temperaturas máximas e mínimas registradas.

A temperatura na peça foi medida na junta soldada e monitorada através de um conjunto de termopares ligados a um termoregistrador. Foram instalados, pelo lado interno do tubo na direção da solda, três termopares do tipo $\mathrm{K}$ em cada junta soldada, totalizando 6 termopares, como mostra a Figura 2. A instalação foi feita antes da montagem do aparato e a fixação dos termopares foi efetuada pelo método de solda por pontos. O objetivo foi registrar as temperaturas máximas e mínimas, no centro da junta, alcançadas durante a soldagem em cada procedimento. Utilizou-se também um pirômetro ótico para medir a temperatura entre passes e a temperatura das peças durante a soldagem.
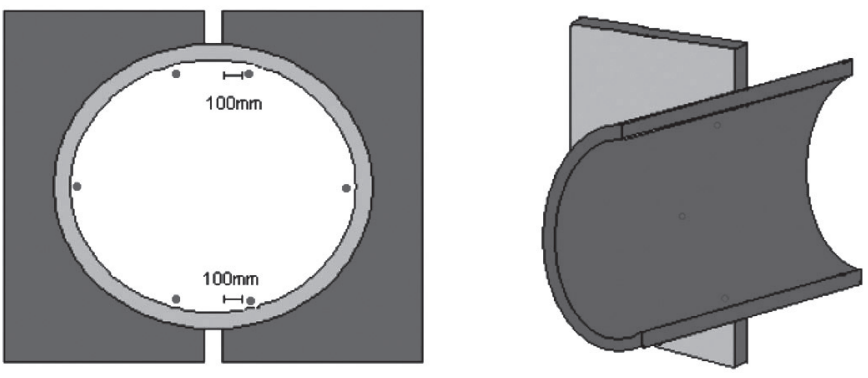

B

(b)

Figura 2. Detalhes dos instrumentos utilizados para a monitoração da temperatura. (a) Termômetro, termopar e termo-registrador. (b) posição de instalação dos temopares internos.

Tabela 1. Variáveis do fluxo no interior do tubo.

\begin{tabular}{|c|c|}
\hline Fluido & Água \\
\hline Pressão do Fluido $\left(\mathrm{kg} / \mathrm{cm}^{2}\right)$ & 0,2 \\
\hline Vazão do Fluido $(1 / \mathrm{s})$ & 0,6 \\
\hline Velocidade de Escoamento do Fluido $(\mathrm{m} / \mathrm{s})$ & 0,002 \\
\hline Número de Reynolds & 806 \\
\hline Regime de Fluxo & Escoamento Laminar \\
\hline
\end{tabular}


A taxa de resfriamento da peça $\left(\Delta \mathrm{T}_{350-150}\right)$ entre $350^{\circ} \mathrm{C}$ e $150^{\circ} \mathrm{C}$ foi estimada. A metodologia usada consistiu em aquecer localmente o tubo em uma região próxima à solda, utilizando um maçarico oxi-acetileno como fonte de calor. O tubo foi aquecido até $400^{\circ} \mathrm{C}$, em seguida a chama foi interrompida e iniciou-se a contagem do tempo de resfriamento a partir de $350^{\circ} \mathrm{C}$ até $150^{\circ} \mathrm{C}$, usando um pirômetro ótico e um cronômetro. A taxa de resfriamento foi calculada $\mathrm{em}^{\circ} \mathrm{C} / \mathrm{s}$. Foram realizadas cinco medições, sendo calculada a média dos resultados. Este procedimento foi realizado para duas espessuras do tubo (11 $\mathrm{mm}$ e $6 \mathrm{~mm}$ ) e para as duas temperaturas do fluido (temperatura ambiente e $10^{\circ} \mathrm{C}$ ). Também foi medida para os tubos sem fluxo interno, que representa o procedimento de soldagem convencional, sem flúido de arrefecimento, para efeito de comparação.

Ensaios Não Destrutivos: após a soldagem, $100 \%$ das juntas soldadas foram submetidas à inspeção visual, líquido penetrante, partículas magnéticas e ultra som. Os ensaios foram conduzidos de acordo com a norma ASME Section V [9] por inspetores qualificados.

Ensaios Mecânicos: Apenas as juntas de espessura $11 \mathrm{~mm}$ (Q11 e F11) foram avaliadas, por meio dos ensaios de impacto Charpy V, tração, fratura, dureza e dobramento. A Tabela 2 mostra a quantidade de corpos de prova usados. Os ensaios foram programados com base nas especificações de fabricação dos materiais e nas normas aplicáveis na qualificação dos procedimentos de soldagem, no caso as normas API 1104 [10] e ASME Seção IX [11]. A localização e orientação para a retirada dos corpos de prova são mostradas na Figura 3. Os ensaios foram conduzidos de acordo com a norma ASTM A 370 [12], seguindo os critérios de aceitação referentes à qualificação destes procedimentos de soldagem, ASME IX [11] e API 1104 [10].

Tabela 2. Ensaios Destrutivos Realizados.

\begin{tabular}{|c|c|c|c|c|}
\hline & $\begin{array}{c}\text { Total de Corpos } \\
\text { de Prova }\end{array}$ & Q11 & F11 & Metal Base \\
\hline Tração & 5 & 2 & 2 & 1 \\
\hline Dobramento & 8 & 4 & 4 & - \\
\hline Impacto & 15 & 6 & 6 & 3 \\
\hline Fratura & 8 & 4 & 4 & - \\
\hline
\end{tabular}
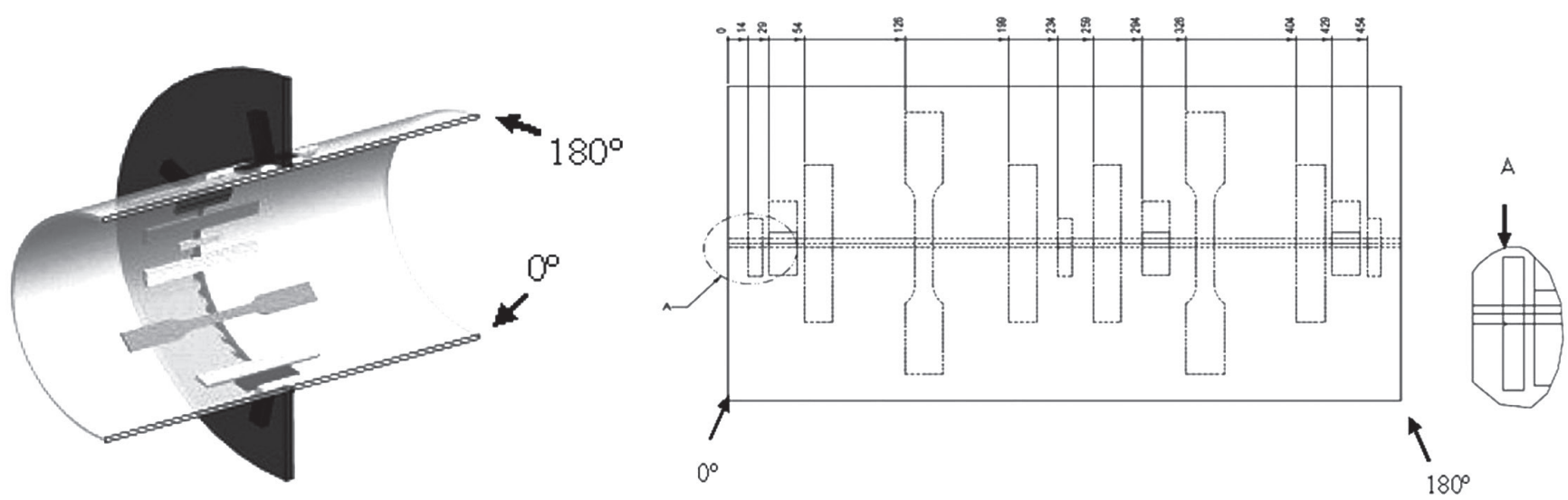

Figura 3. Orientação para Retirada dos CP. 

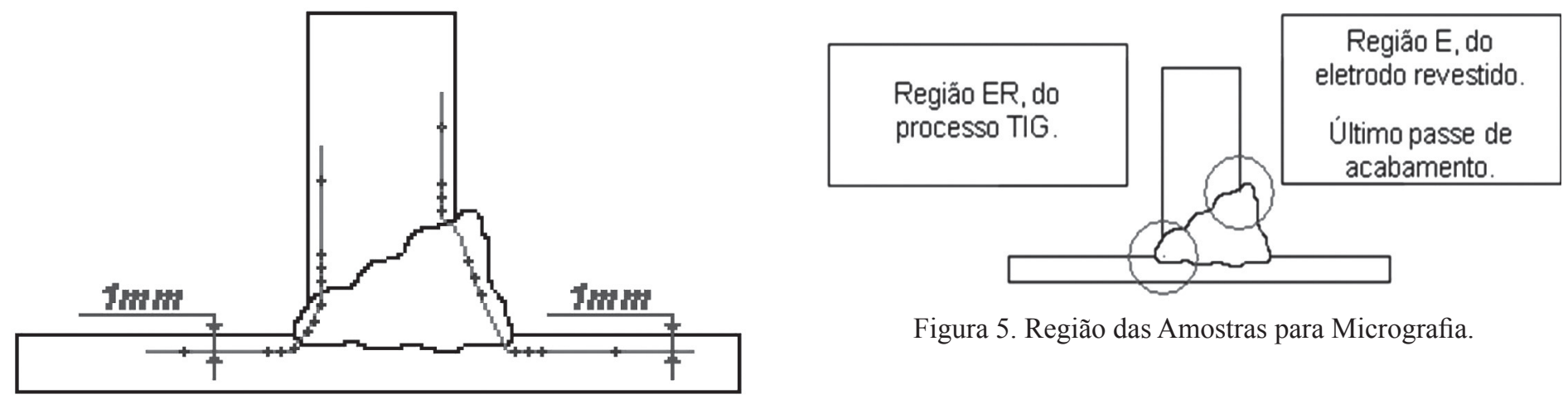

Figura 5. Região das Amostras para Micrografia.

Figura 4. Arranjo para Medição de Dureza.

Tabela 3. Composição Química dos Materiais de Base.

\begin{tabular}{|c|c|c|c|c|}
\hline \multicolumn{5}{|c|}{ Composição Química } \\
\hline \multirow{2}{*}{ Elemento } & \multicolumn{2}{|r|}{ Tubo } & \multicolumn{2}{|r|}{ Chapa } \\
\hline & Ensaio & Norma (máx) API 5L & Ensaio & Norma (máx) ASTM A105 \\
\hline $\mathrm{C}(\%)$ & 0,188 & 0,24 & 0,22 & 0,35 \\
\hline $\operatorname{Mn}(\%)$ & 1,24 & 1,40 & 1,17 & 1,35 \\
\hline $\mathrm{Cr}(\%)$ & 0,007 & - & 0,017 & 0,30 \\
\hline Mo (\%) & 0,044 & - & 0,002 & 0,12 \\
\hline $\mathrm{V}(\%)$ & 0,054 & 0,10 & 0,001 & 0,08 \\
\hline $\mathrm{Ni}(\%)$ & 0,05 & - & 0,002 & 0,40 \\
\hline $\mathrm{Cu}(\%)$ & 0,003 & - & 0,003 & 0,40 \\
\hline $\mathrm{CE}(\%)$ & 0,42 & 0,43 & 0,42 & 0,48 \\
\hline \multicolumn{5}{|c|}{$\mathrm{CE}(\%)=(\% C)+\underline{(\% \mathrm{Mn})}+\underline{(\% \mathrm{Cr})+(\% \mathrm{~V})+(\%(\mathrm{Mo})}+\underline{(\% \mathrm{Ni})+(\% \mathrm{Cu})}$} \\
\hline
\end{tabular}

Tabela 4. Parâmetros de Soldagem.

\begin{tabular}{|c|c|c|c|c|c|c|c|c|}
\hline \multirow{9}{*}{ 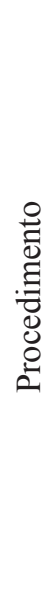 } & & 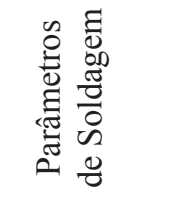 & 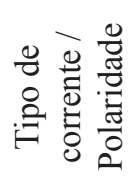 & 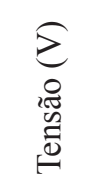 & $\begin{array}{l}\text { ड़ } \\
0 \\
0 \\
0 \\
0 \\
0\end{array}$ & 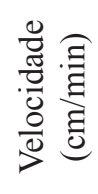 & 毞 & 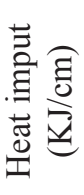 \\
\hline & \multirow{4}{*}{ Q11 } & Raiz & CCPD & 13 & 148 & 3 & 7 & 38,5 \\
\hline & & Reforço & CCPD & 11,5 & 141 & 6 & 8 & 16,2 \\
\hline & & Enchimento & CCPI & $24-26$ & $140-150$ & $10-22$ & $7-10$ & 21,0 \\
\hline & & Acabamento & CCPI & 26 & 100 & $11-20$ & $7-8$ & 14,2 \\
\hline & \multirow{4}{*}{ F11 } & Raiz & CCPD & 14 & 205 & 7,5 & 7,1 & 23,0 \\
\hline & & Reforço & CCPD & 15,2 & 226 & 12 & 10 & 17,2 \\
\hline & & Enchimento & CCPI & $25-29$ & $130-150$ & $7-20$ & $9-11$ & 30,1 \\
\hline & & Acabamento & CCPI & $28-30$ & $11-105$ & $11-17$ & $8-9$ & 15,8 \\
\hline
\end{tabular}

Execução da Soldagem: a Tabela 4 mostra os parâmetros de soldagem utilizados e o cálculo do aporte de calor (HI) conforme a equação 1 abaixo.

$H I(\mathrm{KJ} / \mathrm{cm})=0,06 \times \frac{\text { corrente }(A) \times \text { tensão }(\mathrm{V})}{\text { velocidade }(\mathrm{cm} / \mathrm{min})}$

Equação 1

\section{Resultados e Discussão}

Análise Química: a Tabela 3 mostra que a composição química do tubo atendeu às exigências da norma API 5L para este material. O CE foi calculado em $0,42 \%$, próximo do limite máximo previsto para o grau X-60, que é de $0,43 \%$. A composição da chapa ASTM A105 também atendeu à especificação, com CE calculado em $0,42 \%$, sendo o máximo permitido de $0,48 \%$ para este material. Tanto o tubo como a chapa foram cuidadosamente escolhidos para este trabalho, de forma que o $\mathrm{CE}$ de ambos estivessem próximos ao limite máximo das especificações, pois na soldagem, altos valores de CE implicam em uma maior susceptibilidade a formação de estruturas frágeis e trincas a frio [3]. 
Ensaios Não Destrutivos: foram realizados de acordo com os métodos previstos. Ensaio visual, LP e PM não mostraram evidências de descontinuidades. O ensaio de US não detectou descontinuidades internas. As juntas foram consideradas aprovadas conforme os critérios de aceitação das normas ASME B 31.3 [14], ASME seção IX [11] e API 1104 [10].

A seguir são apresentados apenas os resultados dos procedimentos com espessura $11 \mathrm{~mm}$ (Q11 e F11). Outro trabalho apresentará os resultados com espessura $6 \mathrm{~mm}$.

Controle da Temperatura durante a Soldagem: a Tabela 5 mostra que a temperatura do fluido foi entre 26 e $36^{\circ} \mathrm{C}$ para o procedimento Q11 e entre 6 e 10 para F11, como previsto. A máxima temperatura interna da parede do tubo foi de $338{ }^{\circ} \mathrm{C}$ no procedimento Q11 e $298^{\circ} \mathrm{C}$ em F11. A norma N-2163 [1] especifica que, para evitar perfuração durante a soldagem em operação, a temperatura interna da parede deve ser inferior a 980 ${ }^{\circ} \mathrm{C}$. Conclui-se que para Q11 e F11 a temperatura interna do tubo está abaixo da máxima especificada por norma, minimizando a possibilidade de perfuração durante a soldagem. A taxa de resfriamento medidas foi de $37,5{ }^{\circ} \mathrm{C} / \mathrm{s}$ para Q 11 e $50{ }^{\circ} \mathrm{C} / \mathrm{s}$ para F11. A taxa de resfriamento para o mesmo tubo sem o fluxo utilizado em procedimentos convencionais de soldagem sem fluxo é de $2^{\circ} \mathrm{C} / \mathrm{s}$. Pode-se concluir que o efeito do arrefecimento do flúido no tubo foi mais significativo que a temperatura deste fluido.

Tabela 5. Intervalos das Temperaturas Registradas.

\begin{tabular}{|c|c|c|c|c|}
\hline \multicolumn{2}{|c|}{} & Q11 & F11 & $* *$ \\
\hline \multirow{2}{*}{ Tubo $\left({ }^{\circ} \mathrm{C}\right)$} & mínima & 25,6 & 6,7 & - \\
\cline { 2 - 5 } & máxima & 31,8 & 10 & - \\
\hline \multirow{2}{*}{ Liquido $\left({ }^{\circ} \mathrm{C}\right)$} & mínima & 26 & 6 & - \\
\cline { 2 - 5 } & máxima & 36 & 10 & - \\
\hline \multirow{2}{*}{ Termopares Internos $\left({ }^{\circ} \mathrm{C}\right)$} & mínima & 221 & 250 & - \\
\cline { 2 - 5 } & máxima & 338 & 298 & - \\
\hline \multicolumn{2}{|c|}{$\Delta \mathrm{t}(300-150)\left({ }^{\circ} \mathrm{C} / \mathrm{s}\right)$} & 37,5 & 50 & 2 \\
\hline \multicolumn{2}{|c|}{$*$ Sem líquido interno } & & & \\
\hline
\end{tabular}

Macrografia: a figura 6 mostra as regiões da junta soldada, a quantidade de passes e camadas, a transição entre o metal de adição e o metal de base e identifica a extensão da ZTA. A macrografia foi considerada aprovada.

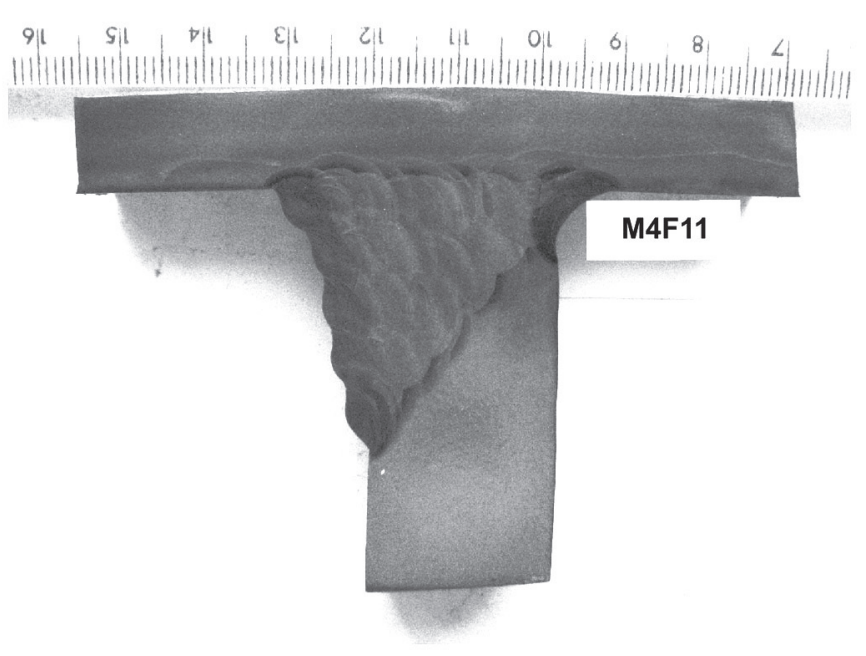

Figura 6. Macrografia típica, relativa ao procedimento F11.

Ensaio de Tração: a Tabela 6 mostra que tanto o tubo usado (metal base) como as juntas soldadas Q11 e F11 atenderam os requisitos da norma API 5L PSL-2 [15]. Nota-se uma relativa queda no alongamento das juntas soldadas, quando comparado ao metal base. A queda na ductilidade é atribuída ao arrefecimento do fluido.

Fratura (Nick Break): o objetivo deste ensaio [10] é atestar a inexistência de defeitos nas juntas soldadas. Os ensaios dos $8 \mathrm{CP}$ não evidenciaram descontinuidades significativas, sendo considerados aprovados.

Ensaio de Dobramento: não foram constatadas descontinuidades acima de $3 \mathrm{~mm}$ na região de dobramento, sendo considerados aprovados conforme [10].

Dureza vickers: a tabela 7 mostra os resultados obtidos (média, desvio padrão e coeficiente de variância). O valor máximo encontrado foi de $280 \mathrm{HV}$, para a ZF da junta Q11. A tabela 7 mostra um acréscimo na dureza da ZF e da ZTA para ambos os procedimentos Q11 e F11 em comparação aos metais de base (chapa e tubo). Os consumíveis de soldagem utilizados (tig e eletrodo revestido) apresentam dureza entre 180 e 220 HV [7,8] quando usados na soldagem convencional, sem arrefecimento. O aumento da dureza foi atribuído ao efeito do arrefecimento do fluido interno, que aumentou significativamente a taxa de resfriamento (veja tabela 5). Por outro lado, observa-se que a

Tabela 6. Resultados dos Ensaios de Tração.

\begin{tabular}{|c|c|c|c|c|c|c|c|c|}
\hline & \multicolumn{2}{|c|}{ Escoamento (MPa) } & \multicolumn{2}{|c|}{ Resistência (MPa) } & \multicolumn{2}{|c|}{ Alongamento (\%) } & \multirow{2}{*}{$\begin{array}{c}\text { Redução de Área } \\
(\%)\end{array}$} & \multirow{2}{*}{ FRATURA } \\
\hline & ensaio & Ref. [15] & ensaio & Ref. [15] & Ensaio & Ref. [15] & & \\
\hline MB & 498 & \multirow{3}{*}{$\begin{array}{c}415 \\
\text { (Mín.) }\end{array}$} & 586 & \multirow{3}{*}{$\begin{array}{c}520 \\
\text { (Mín.) }\end{array}$} & 33,8 & 20 (Mín.) & 70,0 & - \\
\hline \multirow{2}{*}{ Q11 } & 507 & & 590 & & 21,2 & \multirow{4}{*}{$\begin{array}{c}20 \\
\text { (Mín.) }\end{array}$} & 62,2 & MB \\
\hline & 485 & & 535 & & 20,8 & & 70,4 & MB \\
\hline \multirow{2}{*}{ F11 } & 519 & 565 & 605 & \multirow{2}{*}{$\begin{array}{c}760 \\
(\operatorname{Max})\end{array}$} & 22,8 & & 56,8 & MB \\
\hline & 515 & $(\operatorname{Max})$ & 596 & & 20,2 & & 43,7 & $\mathrm{ZF}$ \\
\hline
\end{tabular}


redução da temperatura do fluido interno de $26-36^{\circ} \mathrm{C}$ para $6-10$ ${ }^{\circ} \mathrm{C}$ não influenciou significativamente os resultados de dureza.

Os resultados da dureza ratificam os valores obtidos nos ensaios de tração (veja tabela 6) tendo sido observado um aumento da dureza acompanhado com um aumento do limite de resistência e queda da ductilidade.

Tabela 7. Média e desvio padrão do ensaio de dureza vickers com carga de $10 \mathrm{kgf}$.

\begin{tabular}{|c|c|c|c|c|}
\hline \multirow{2}{*}{ Metal Base } & Região & $\begin{array}{c}\text { Média } \\
(\mathrm{HV})\end{array}$ & $\begin{array}{c}\text { Desvio } \\
\text { Padrão }\end{array}$ & Coef. de Var. \\
\cline { 2 - 5 } & Tubo & 187 & 15 & 3 \\
\hline \multirow{3}{*}{ F11 } & Chapa & 229 & 16 & 3 \\
\hline \multirow{3}{*}{ Q11 } & ZTA & 255 & 25 & 10 \\
\cline { 2 - 5 } & ZF & 269 & 23 & 8 \\
\cline { 2 - 5 } & ZTA & 263 & 14 & 5 \\
\hline
\end{tabular}

Ensaio de Impacto: os resultados são mostrados na Tabela 8. A energia absorvida (EA) pelo metal base foi $268 \mathrm{~J}$. Os procedimentos Q11 e F11 apresentaram EA convertida acima da do metal base. A norma API 5L PSL-2 [15] estabelece para o Grau X60 o mínimo de $27 \mathrm{~J} \mathrm{a} 0{ }^{\circ} \mathrm{C}$. Assim, tanto o arrefecimento como a temperatura do fluido interno não alteraram a tenacidade da ZF e da ZTA.

Os resultados dos ensaios apresentados acima (ensaios não destrutivos, dobramento, fratura, tração, dureza e impacto) permitem aprovar e qualificar o procedimento de soldagem conforme ASME seção IX [11] para a soldagem em operação de tubo com $11 \mathrm{~mm}$ de espessura com fluido interno até a temperatura mínima de $6-10{ }^{\circ} \mathrm{C}$.

Microstrutura: foi avaliada apenas a amostra Q11, que apresentou maior dureza na ZF. A microstrutura do MB (tubo) é constituida de uma fina ferrita poligonal, figura 7. A ZF é constituída de ferrita acicular e ferrita poligonal, com alguma ferrita com segunda fase alinhada, figura 8. A região de grãos finos (RGF) da ZTA é constituída de uma fina ferrita poligonal, figura 9. A região de grãos grosseiros (RGG) da ZTA é constituída predominantemente de ferrita de widmanstatten. Não há evidências de fases frágeis. A microestrutura obtida é compatível com os resultados de dureza (tabela 7) e tenacidade ao impacto (tabela 8).

Tabela 8. Resultados do ensaio de impacto Charpy $\mathrm{V}$ a $0{ }^{\circ} \mathrm{C}$.

\begin{tabular}{|c|c|c|c|c|c|c|c|c|}
\hline \multirow{2}{*}{ CP } & Dimensão (mm) & Entalhe & \multicolumn{3}{|c|}{ Energia Absorvida (J) } & Média (J) & Média da EA Convertida (J) & API 5L PSL-2 [15] (J) \\
\hline MB & $55 \times 10 X 10$ & MB & 266 & 266 & 273 & 268 & 268 & 27 (mín) \\
\hline \multirow{2}{*}{ Q11 } & $55 \times 10 \times 7,4$ & ZF & 209 & 201 & 203 & 204 & 272 & \multirow{2}{*}{27 (mín) } \\
\cline { 2 - 10 } & $55 \times 10 \times 7,4$ & ZTA & 203 & 216 & 199 & 206 & 274 & 355 \\
\hline \multirow{2}{*}{ F11 } & $55 \times 10 \times 7,4$ & ZF & 237 & 273 & 279 & 263 & 332 & \\
\cline { 2 - 9 } & $55 \times 10 \times 7,4$ & ZTA & 227 & 251 & 261 & 246 & & \\
\hline
\end{tabular}

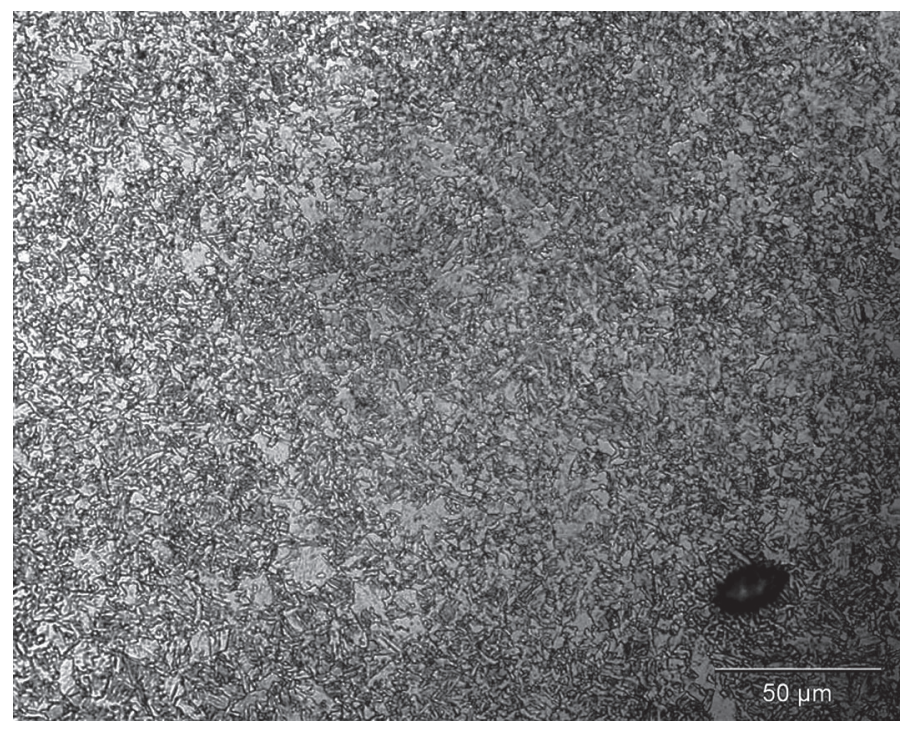

Figura 7. Metal base (tubo) 400X.

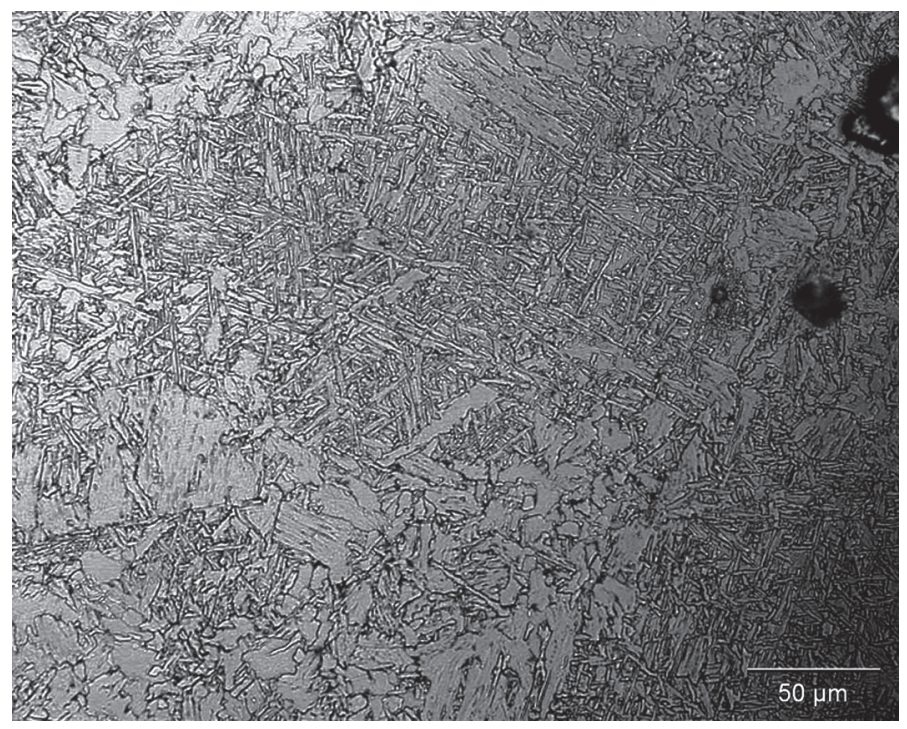

Figura 8. Zona fundida 400X. 


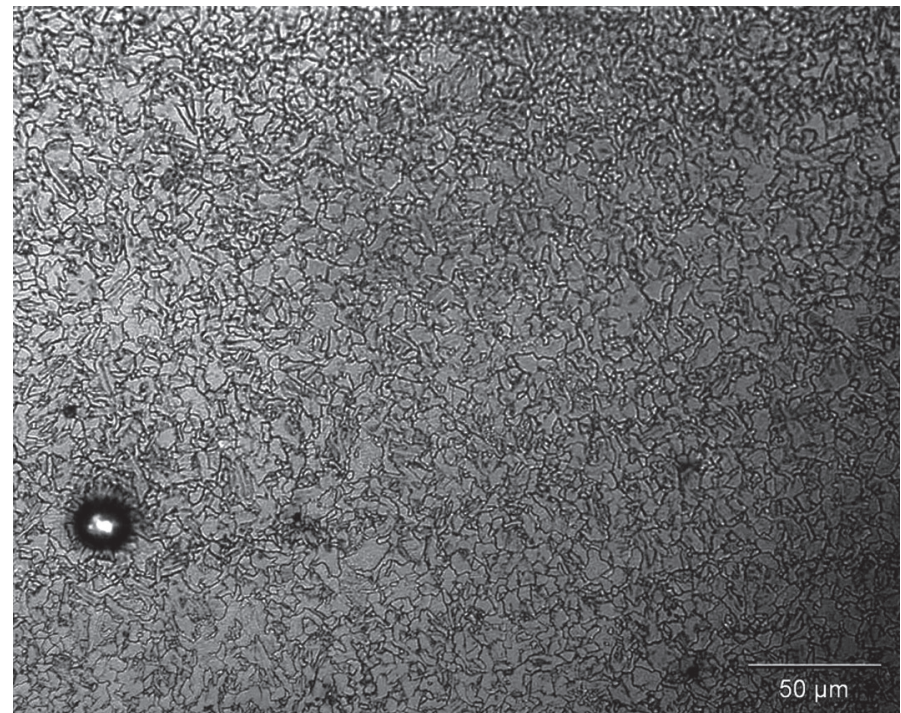

Figura 9. Região de grãos finos da ZTA (TIG, tubo) 500X

\section{Conclusões}

A avaliação na soldagem em operação da influência do arrefecimento causado pelo fluido em contato com a parede interna de uma tubulação de $11 \mathrm{~mm}$ espessura, utilizando os processos de soldagem TIG (GTAW) e Eletrodo Revestido (SMAW) permite concluir que:

$\mathrm{Na}$ soldagem em operação, o resfriamento causado pelo fluido em circulação, elevou significativamente a taxa de resfriamento na superfície interna do tubo, quando comparado à soldagem convencional, sem arrefecimento.

$\mathrm{O}$ efeito do arrefecimento do fluido no interior do tubo foi mais significativo que a temperatura deste fluido.

$\mathrm{O}$ arrefecimento causado pelo fluido provocou aumento na dureza da ZF e ZTA, e reduziu o alongamento no ensaio de tração, porém ainda em valores adequados para o tubo de $11 \mathrm{~mm}$ de espessura. Demais propriedades não foram alteradas.

Foi possível, pelos resultados dos ensaios não destrutivos e ensaios mecânicos obtidos, qualificar o procedimento de soldagem, com base nas normas especializadas neste processo.

Com o procedimento de soldagem adotado, não é necessária a adoção de cuidados especiais quanto à possibilidade de perfuração e vazamento de fluido de processo, visto que a temperatura máxima na parede interna do tubo foi de $338^{\circ} \mathrm{C}$.

\section{Referências Bibliográficas}

[1] PETROBRAS N-2163. "Soldagem e Trepanação em Equipamentos, Tubulações Industriais e Dutos em Operação". Brasil, 2008.

[2] COE, F. R. "Welding Steels Without Hydrogen Cracking". The Welding Institute, Cambridge, United Kingdon. 68p., 1973 [3] MODENESI, P. J. "Soldabilidade dos Aços Transformáveis". Departamento de Engenharia Metalúrgica da Universidade Federal de Minas Gerais. Belo Horizonte, MG. 71p. 2006.

[4] BRUCE, W. A. "Overview of In-service Welding Research

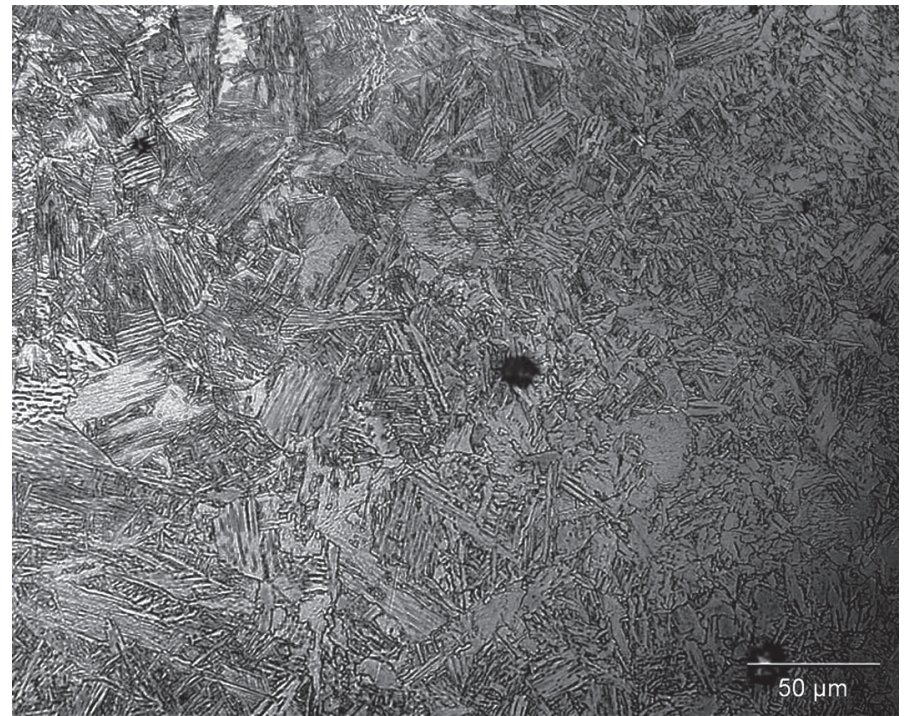

Figura 10. Região de grãos grosseiros da ZTA (TIG, chapa) $400 \mathrm{X}$.

at EWI". First International Conference on Welding Onto InService Petroleum Gas and Liquid Pipelines. WollongongAustralia. 2000.

[5] FARIA, P. Efeito do Arrefecimento do Fluido e da Espessura do Material na Soldagem em Operação em Plantas Offshore. Dissertação (Mestrao em Engenharia e Ciência dos Materiais) Campos dos Goytacazes - RJ Universidade Estadual do Norte Fluminense, UENF, 185p., 2011.

[6] ASTM A105. "Standard Specification for Carbon Steel Forgings for Piping Applications". American Society for Testing and Materials. USA. 5p. 2010.

[7] AWS A 5.18. "Specification for Carbon Steel Electrodes and Rods for Gas Shielded Arc Welding”. American Welding Society, USA. 44p. 2005.

[8] AWS A 5.1. "Specification for Carbon Steel Electrodes for Shielded Metal Arc Welding”. American Welding Society, USA. 55p. 2005.

[9] ASME Section V. Non Destrutive Examination. American Society for Mechanical Engineers. USA. 304p. 2007.

[10] API 1104. Standard for Welding Pipe Lines and Related Facilities. American Petroleum Institute, USA. 50p. 2010.

[11] ASME Section IX. Qualification Standard For Welding And Brazing Procedures, Welders, Brazers, And Welding And Brazing Operators. American Society for Mechanical Engineers. USA. 245p. 2008.

[12] ASTM A 370. Standard Test Methods and Definitions for Mechanical Testing of Steel Products. American Society for Testing and Materials, USA. 47p. 2008.

[13] ASTM E 92. Standard Test Method for Vickers Hardness of Metallic Materials. American Society for Testing and Materials, USA. 9p. 2003.

[14] ASME B 31.1. Process Piping. American Society for Mechanical Engineers, USA. 386p.

[15] API 5L PSL-2. Specification for line pipes. American

Petroleum Institute, USA. 186p. 2009. 